\title{
Exploiting suction to reduce embodied carbon in geotechnical structures
}

\author{
D. McIntyre and A. Tarantino \\ Department of Civil and Environmental Engineering, University of Strathclyde, Glasgow, UK
}

\begin{abstract}
The targets set out in the Climate Change Act 2008 mean that the commitment to cut the CO2 emissions of the United Kingdom is now a matter of legal obligation. Similar legislation is being promulgated in several countries worldwide. The construction industry must therefore develop new techniques for design in order to survive in the 'low-carbon economy'. A study was undertaken to examine whether the inclusion of negative pore-water pressures (or 'soil suction') in the design of a flood embankment could reduce the embodied carbon in the structure. The study found that fully utilising the effects of soil suction in the design could yield potential savings of over $50 \%$ in materials. In terms of embodied carbon, this equates to removing 2.3 million car-kilometres from the road for each kilometre of embankment constructed using the new design concept.
\end{abstract}

\section{INTRODUCTION}

The consequences of climate change are increasingly being felt in Europe and worldwide. The average global temperature continues to rise and some natural processes are being altered, e.g. precipitation patterns are changing and glaciers are melting.

Construction is one of the main sectors responsible for carbon emissions and geotechnical engineering will play a pivotal role in addressing the climate change challenge. Geotechnical engineers will be challenged to design carbon-efficient geoinfrastructures by making use of environmentallyfriendly geomaterials and reinforcements and developing new design concepts.

Suction is commonly neglected in geotechnical design. However, suction is an extraordinary untapped natural 'reinforcement' and, if accounted for in geotechnical design, could significantly contribute to reduce financial and carbon cost of a geostructure.

This paper aims at examining whether, and to what extent, the inclusion of soil suction in geotechnical design could reduce the embodied carbon. The analysis is developed herein with reference to an ideal flood embankment.

\section{BACKGROUND}

\subsection{Conventional design of flood embankments}

Hydraulic loads on flood embankments are currently applied using a 'steady state' approach (USACE,
2000). For example, a simple flownet is used to analyse seepage during flood conditions, which may be generated using widely available steady-state seepage software. The pore water pressures can be obtained from the software and used to analyse the stability of the slope, all with a great deal of ease. However, there is one major drawback with this approach, as it is easy to overlook a fundamental assumption: the use of a steady-state analysis assumes that the steady state will be reached in practice. Due to the very nature of a flood defence, the embankment will only be expected to perform as a dam during discrete, infrequent flooding events. These floods may be expected to last a period of say several hours to several days. When soils with relatively low permeability are involved the steady-state in the embankment may not occur for several weeks or months and embankments will therefore remain largely unsaturated during flood events. As a result, to use a steady-state analysis will very often produce an absurdly over-conservative design (Kerkes and Fassett, 2006).

\subsection{Climate change and Embodied carbon}

The commitment to cut the $\mathrm{CO}_{2}$ emissions is now a matter of legal obligation in several countries worldwide including the UK. For example, around $10 \%$ of the $\mathrm{CO}_{2}$ emissions in the $\mathrm{UK}$ are directly associated with the manufacture and transport of construction materials, and the operations on site (Construction Excellence, 2008 as cited by UKGBC, 2013). Coupled with the legal obligation to reduce 
carbon emission, there is also a growing commercial interest in carbon efficient design as companies strive to succeed in a low-carbon economy.

It is clear that climate change will require the industry to change its attitude towards design: it is not acceptable to use a more conservative design as a way blindly catering for future changes. Instead, innovative methods of analysis are needed to ensure that structures can perform in the future. These innovative methods are not only required for new structures; due to the limited supply of money and time there is a need to find new ways of prioritising work on existing infrastructure.

\section{METHODOLOGY}

\subsection{Constitutive relations}

The model was constructed to represent a river channel in a homogeneous soil layer which extends down to an impermeable layer. It was decided that the soil would be a 'silty sand' with properties extracted from the literature.

To ensure that the predictions of the embankment model were a reasonable reflection of reality, soil properties from a real flood embankment were used. Zielinski et al. (2011) conducted extensive waterretention tests on a soil used for the construction of a flood embankment near the town of Galston in East Ayrshire; this offered a prime opportunity to use data from a local project. In instances where additional soil parameters were required (e.g. saturated hydraulic conductivity), estimates were made using empirical relationships found in the literature.

Water retention data from Galston material were fitted using van Genuchten (1980) function:

$\theta_{\theta}=\left[\frac{1}{1+(\alpha s)^{n}}\right]^{m}$

$\theta_{e}=\frac{\theta-\theta_{r}}{\theta_{s}-\theta_{r}}$

where: $\theta=$ water content, $\theta_{\mathrm{e}}=$ normalized water content, $\theta_{\mathrm{s}}=$ saturated water content, $\theta_{\mathrm{r}}=$ residual water content, $s=$ suction.

Relative hydraulic conductivity function was derived as follows:

$$
\begin{aligned}
& k_{r}(\theta)=\sqrt{\theta_{\theta}}\left[1-\left(1-\theta_{\theta}{ }^{1 / m}\right)^{m}\right]^{2} \\
& k_{r}(\theta)=\frac{k(\theta)}{k_{\text {sat }}}
\end{aligned}
$$

where: $k(\theta)=$ conductivity function, $k_{r}(\theta)=$ normalised conductivity function, $k_{\text {sat }}=$ saturated conductivity.

Shear strength was modelled according to Vanapalli et al. (1996):

$\tau=\sigma_{n} \tan \phi^{\prime}+s\left[\theta_{\theta} \tan \phi^{\prime}\right]$

where: $\tau=$ shear strength, $\phi '=$ angle of friction, $\sigma_{\mathrm{n}}=$ normal stress, $s=$ suction

\subsection{Water flow analysis}

The software package used in the analysis was GeoStudio 2007 (by GEO-SLOPE International Ltd., Alberta, Canada), which contained a seepage modeling program and a slope-stability analysis program. The seepage software is a finite element analysis program which is capable of computing flows, pressures, etc in both saturated and unsaturated soils. The software is able to handle both steadystate and transient analyses. The slope-stability program is able to use a variety of calculation methods to assess stability and Bishop's method was chosen. The software package is designed such that the porewater pressure results gained in a seepage analysis can be used in the slope stability analysis.

\subsection{Model design}

As the hypothetical river channel was symmetrical, it was sufficient to model one side only: Figure 1 shows the model which was used. The boundary conditions shown relate to a transient analysis examining the seepage behaviour during the river in flood: these boundary conditions were chosen after careful consideration of the problem. The axis of symmetry on the left hand edge of the model was assigned a $q=0 \mathrm{~m}^{3} / \mathrm{s}$ (i.e. zero flux) condition, as was the lower edge of the model which is assumed to be an impermeable layer. The river channel and the 'wet' side of the embankment were assigned a constant head boundary condition of $\mathrm{H}=4.5 \mathrm{~m}$ to simulate the hydrostatic pressure from the river in flood. The right hand edge of the model was assigned a constant head of $\mathrm{H}=0 \mathrm{~m}$ to represent the hydrostatic conditions of the far-field groundwater. All other edges were assigned a 'potential seepage face' boundary condition, which means that the program will assign a zero flux boundary condition unless the total head at a point increases to a value greater than its elevation, in which case the boundary condition changes to a zero-pressure condition (GeoSlope, 2010). The last condition to be specified is the initial water table, which was drawn as a horizontal line at $\mathrm{H}=0 \mathrm{~m}$. 


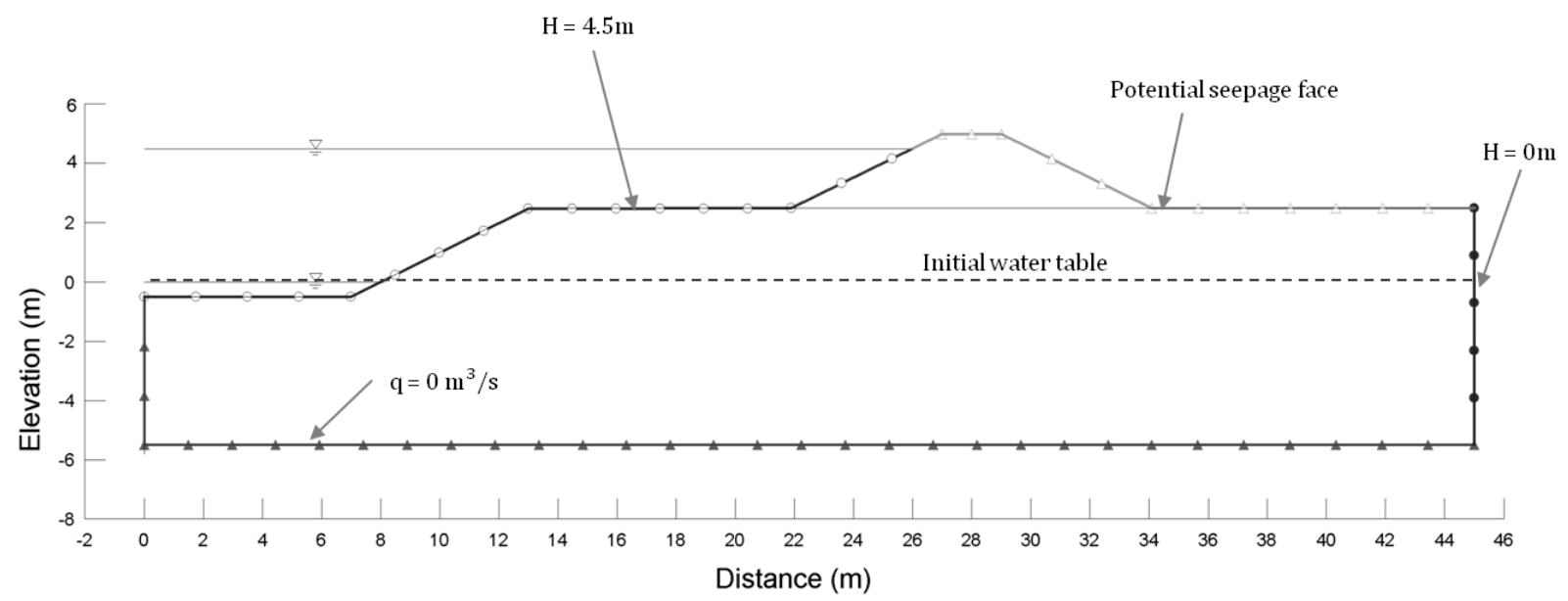

Figure 1- Boundary conditions applied to model for testing

\subsection{Model testing}

In order to create a robust seepage model, many of the settings related to numerical integration of the governing PDEs were tested for their influence on the results.

Figure 2a shows the variation in total head with distance along a line drawn through the embankment for different mesh sizes. Clearly the mesh size has an effect on the model output, and a closer look is required.

Figure $2 \mathrm{~b}$ shows some of the data on a larger scale. Here it is clear that the mesh size has an appreciable effect on the model output: the $1.5 \mathrm{~m}$ mesh produces a very 'rough' profile with few data points. As the mesh size decreases the curve becomes progressivly smoother, and the results will converge towards the 'best' solution. It can be seen that there is very little difference between the results from the smallest mesh sizes, and so it can be concluded that there becomes a point beyond which decreasing the mesh size will not improve the model. Using a mesh size of $0.1 \mathrm{~m}$ takes four times longer to solve than a mesh size of $0.2 \mathrm{~m}$, and as mentioned previously the results are only very slightly improved.

For the purposes of this study, a minimum mesh size of $0.2 \mathrm{~m}$ was deemed sufficient to obtain an accurate model without excessive computational burden. Of course, there are certain areas of the model which will not require such a fine mesh (e.g. at those extremities where the conditions are almost hydrostatic), and so different regions were be given different mesh sizes.

This 'model testing' process was repeated for various parameters (such as integration time-step, mesh element shape, and various model dimensions) to ensure that the results were not adversely affected by the way in which the software was used. It was very important that the model could be relied upon as it forms the foundation upon which the rest of this project is built: any conclusions drawn from an untested model would not be defensible at all.
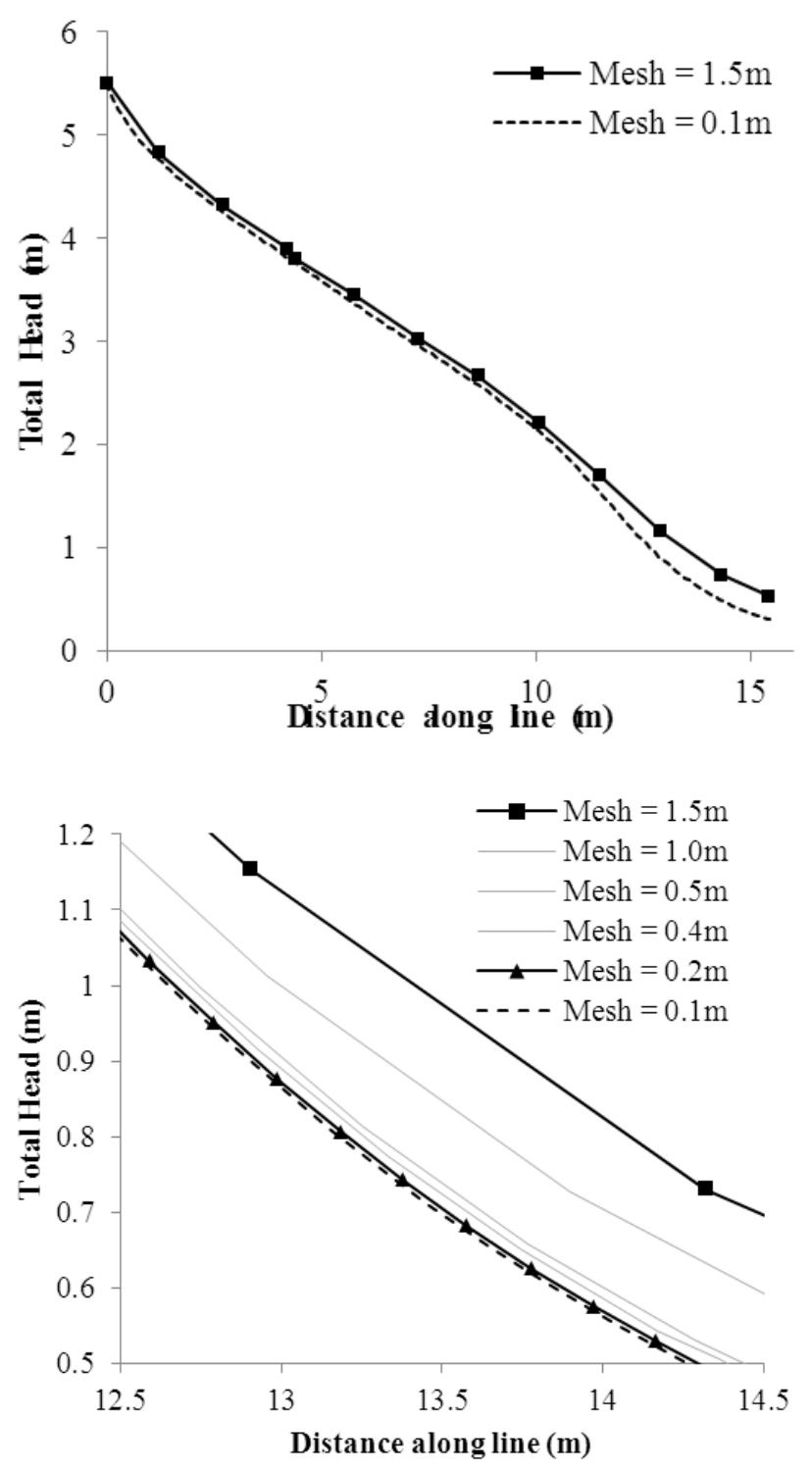

Figure 2 - Variation of Total Head with Distance, for various mesh element sizes

\subsection{Carbon calculation}

Calculation of embodied carbon was accomplished using an industry-standard 'carbon calculator' tool which considers quantity of materials and the distance to the site to yield a 'cradle-to-site' estimate. 
The author was given access to the Road Infrastructure Project Tool v3.1 which is part of Transport Scotland's Carbon Management System (Transport Scotland; Glasgow, UK), which enables carbon emissions to be quantified with relative ease.

There are several assumptions which had to be made when calculating the embodied carbon for this project:

1. Only the embodied carbon from the construction of the earthwork embankment is considered. In a real project there would be other associated works taking place which may be important design considerations.

2. The inventories upon which the calculation tool is based are of course limited, and so it was not possible to obtain an 'emission value' for the specific type of soil used in the embankment. Instead, the most appropriate value (for 'Soil/General Fill') was used in this estimation.

3. To quantify a 'cradle-to-site' value, a distance between the source (e.g. quarry) and the site had to be chosen; an arbitrary value of $10 \mathrm{~km}$ was assumed. The method of transport was assumed to be a 'Rigid HGV'.

\section{RESULTS AND DISCUSSION}

\subsection{Experiment 1 -}

Under the current steady-state methods of analysis, does the inclusion of soil suction make a difference to the maximum allowable slope angle?

As previously discussed, the angle of the slope was varied within the model to examine at what point the slope becomes unsafe. Table 1 shows a summary of the results from this analysis. Firstly, suction was ignored to give a baseline for comparison. In this case, the LHS slope fails at slope angles greater than $14^{\circ}$ (i.e. this is the point beyond which the stability ratio is less than unity); a $14^{\circ}$ slope is approximately 1:4. The RHS slope fails at slope angles greater than $26^{\circ}$ (approximately 1:2). The next row in Table 1 shows the results of the analysis which included the reinforcing effects of soil suction. Again the LHS slope fails after $14^{\circ}$, however the RHS slope fails after $40^{\circ}$ (approximately 1:1.2).

It is interesting to examine the differences between these two sets of figures. The LHS slope was analysed under the 'instantaneous drawdown' condition; this results in a 'shock unloading' of the structure which leaves excess pore-water pressure within the embankment soil. There is only a small area above the phreatic surface where the soil is unsaturated, and so the reinforcing effects of soil suction are barely significant. For this reason, the maximum angle of the LHS slope is not changed by including the effects of suction.

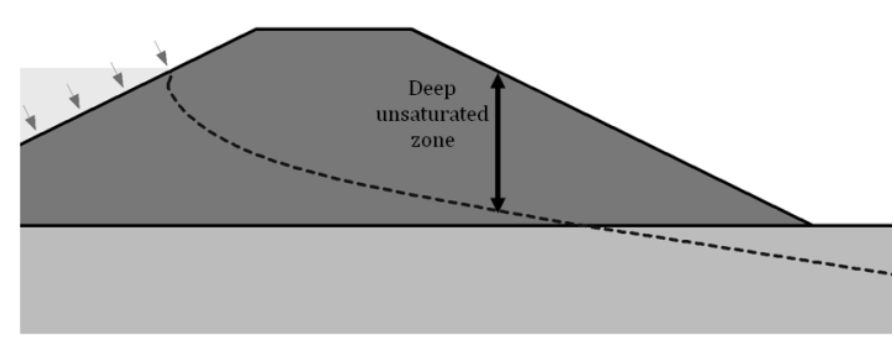

Figure 3 - Typical position of phreatic surface during steady state infiltration from flood

The RHS slope was analysed using a steady-state seepage model; this leaves a large area of the embankment in the unsaturated zone (Figure 3) where suction pressures can influence the stability of the slope. For this reason, the maximum angle of the RHS slope is much greater when suction effects are included.

These figures can be used to compute the saving in cross sectional area which can be achieved when incorporating suction into the traditional 'steady state' embankment design. The bottom row in Table 1 shows the calculated saving.

The inclusion of suction in the design has achieved a saving which is significant, although perhaps not impressive. It is unlikely that a potential saving of $11.2 \%$ would be enough to convince those in industry that the use of 'suction reinforcement' is worth pursuing. Throughout this experiment it was felt that the simplistic 'steady state' method of analysis was restraining the reinforcing effects of soil suction: the next experiments addressed this problem.

Table 1 - Summary table for Experiment 1

\begin{tabular}{|c|c|c|c|}
\hline \multirow{2}{*}{$\begin{array}{l}\text { Steady-State } \\
\text { Approach }\end{array}$} & \multicolumn{2}{|c|}{ Max Slope Angle } & \multirow{2}{*}{$\begin{array}{l}\text { Area } \\
\left(m^{2}\right)\end{array}$} \\
\hline & LHS & RHS & \\
\hline Without suction & $14^{\circ}$ & $26^{\circ}$ & 23.9 \\
\hline With suction & $14^{\circ}$ & $40^{\circ}$ & 21.3 \\
\hline & & Saving & $11.2 \%$ \\
\hline
\end{tabular}

\subsection{Experiment 2}

Could the use of modern, transient methods of analysis allow a steeper slope angle?

For this experiment, soil suction effects were ignored for the time being while impact of the actual design method was investigated. The transient approach considered a 48 hour flood followed by a 6 hour drawdown (these were deemed to be realistic but conservative estimates), compared to the steadystate approach which considered an infinitely long flood followed by instantaneous drawdown. Table 2 shows a summary of the results from this experiment. 
From Table 2, it can be observed that the maximum slope angle of the RHS is not affected by the change to a transient analysis. This is due to the fact that the phreatic surface in the embankment occurs below the failure-surface in both the steady state and 48 hour transient analysis (and hence the pore water does not influence the failure surface in this case).

The transient approach makes a very noticeable difference to the LHS slope (which is controlled by the 'rapid drawdown' condition). This is due to the gradual unloading of the soil over six hours, rather than the 'shock unloading' in the traditional approach: some of the excess pore-water pressure is able to drain from the soil and so the decrease in effective stress is not so large. The entire $25.6 \%$ saving in materials occurs on the LHS slope.

The material saving of $25.6 \%$ is an appreciable amount; this figure may perhaps be enough to at least capture the attention of others who could study this in more detail.

Table 2 - Summary table for Experiment 2

\begin{tabular}{|c|c|c|c|}
\hline \multirow[b]{2}{*}{ Without suction } & \multicolumn{2}{|c|}{ Max Slope Angle } & \multirow{2}{*}{$\begin{array}{l}\text { Area } \\
\left(\mathbf{m}^{2}\right)\end{array}$} \\
\hline & LHS & RHS & \\
\hline Steady-State & $14^{\circ}$ & $26^{\circ}$ & 23.9 \\
\hline Transient & $26^{\circ}$ & $26^{\circ}$ & 17.8 \\
\hline & & Saving & $25.6 \%$ \\
\hline
\end{tabular}

\subsection{Experiment 3}

To what extent could modern, transient methods of analysis be improved further by the inclusion of soil suction?

For this experiment the transient approach was used, and the reinforcing effects of suction were incorporated; the results are summarised in Table 3.

The inclusion of suction into the transient approach makes a very significant difference to the maximum slope angle of the LHS. This can be explained by examining the portion of the embankment which is above the phreatic surface during the drawdown period. If a significant portion of the failure surface lies within the unsaturated zone (see Figure 4), suction becomes very significant and so the embankment did not fail until the slope angle was greater than $46^{\circ}$ (steeper than 1:1). The RHS was also vastly improved by the inclusion of suction; again the failure surface was well within the unsaturated zone and so negative pore-water pressures have a significant effect on the stability.

The overall material saving of $36.8 \%$ is very substantial. This figure should hopefully at least spark an interest for further research into soil suction.

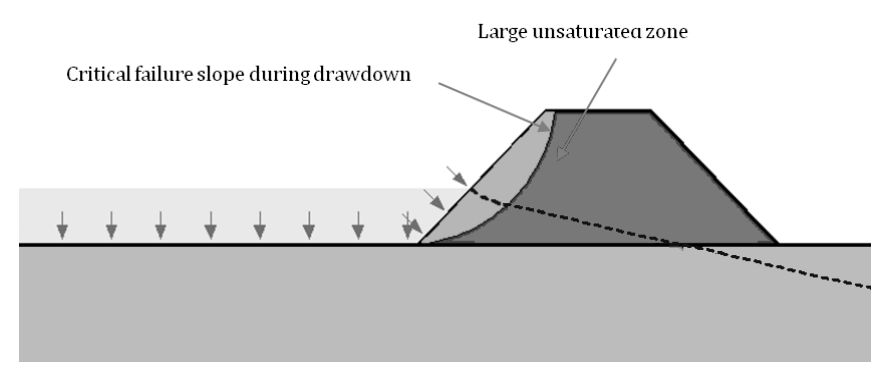

Figure 4 - Position of phreatic surface at most critical stage of drawdown. Note how the large unsaturated zone gives potential for suction reinforcement.

\subsection{Other comparisons}

There is one further comparison that can be made using the above data: a contrast between the steadystate approach which neglects suction (i.e. the 'traditional' approach), and the transient approach which includes suction (i.e. the proposed approach). In this case, the potential saving is $53 \%$. This is very significant, and shows that if the new approach was deemed satisfactory then the material used in the flood embankment could be halved.

Table 3- Summary table for Experiment 3

\begin{tabular}{|l|c|c|c|}
\cline { 2 - 3 } \multicolumn{1}{c|}{$\begin{array}{l}\text { Transient } \\
\text { Approach }\end{array}$} & \multicolumn{2}{|c|}{ Max Slope Angle } & \multirow{1}{*}{} \\
\cline { 2 - 3 } & LHS & RHS & Area $\left(\mathbf{m}^{2}\right)$ \\
\hline Without suction & $26^{\circ}$ & $26^{\circ}$ & 17.8 \\
\hline With suction & $46^{\circ}$ & $44^{\circ}$ & 11.3 \\
\hline \multicolumn{2}{l}{} & Saving & $36.8 \%$ \\
\cline { 3 - 4 }
\end{tabular}

\subsection{Comparison with prior literature}

As previously discussed, soil suction is not considered in normal geotechnical practice; as a result of this, there is very little opportunity to directly compare the results of this study with a real design or case study. However, there are several interesting comparisons which can still be discussed in a more broad sense.

The notion that negative pore water pressure can reinforce a soil slope is by no means a new one. Ching et al (1984) conducted studies on steep natural slopes in Hong Kong, and found that ignoring the effects of suction in the slope-stability analysis resulted in factors of safety which were unrealistically low: when suction was included, the results far better reflected the real situation. The authors of that study felt that the use of 'saturated soil mechanics' principles would detract from the application of sensible engineering solutions. It is felt that the results of this study agree with this statement entirely.

This concept of overdesign also applies to structures other than slopes: Tavakkoli and Vanapalli (2011) showed that including the effects of soil suc- 
tion when designing a retaining wall could result in a reduction in 'lateral earth pressure' of $50 \%$. It is of course not known whether this would translate into a 'material saving' of near $50 \%$, as this would depend on the structure. The interesting point is the magnitude of overdesign in current practice: the results of this study showed the potential for savings of the same magnitude.

\subsection{Quantification of embodied carbon savings}

The overall objective of this study was to examine whether the application of a new science could result in carbon savings. The aforementioned carbon calculation tool was used and the resulting carbon saving due to the proposed approach was found to be 541 tonnes of $\mathrm{CO}_{2}$ per kilometre of embankment constructed. This carbon saving would be equivalent to removing over 2.3 million car-kilometres from the road - equivalent to driving a car around the globe 57 times.

\section{CONCLUSIONS}

\subsection{Key findings from this report}

The utilisation of negative pore-water pressures in the design of a flood embankment has the potential to result in appreciable savings in terms of embodied carbon. The inclusion of suction in the design allows the embankment to be constructed with steeper slopes, thereby reducing the cross-sectional area and hence the quantity of materials used. The savings are very significant: there is potential for savings of over $50 \%$ when the new design is compared to those conducted using outdated 'steady-state' methods without suction. The embodied carbon which could be saved by including suction in the design could be the equivalent of several million car-kilometres per kilometre of embankment constructed.

To reap the full benefits of 'suction reinforcement', the method of designing flood embankments must be modernised. When using the 'steady state' design approach the possible benefits of suction reinforcement are limited: material savings of around $10 \%$ were observed. If the 'transient' method is used, the savings due to suction were found to be almost $40 \%$. Thus to fully realise the benefits of 'soil suction design', the methods of analysis must be improved and modernised.

To conclude, this project has shown that the incorporation of unsaturated soil mechanics into design has the potential to greatly reduce the embodied carbon in a geotechnical structure. It is hoped that this study may contribute in some way to the acceptance of a new technique into regular engineering practice.

\section{ACKNOWLEDGMENTS}

The authors wish to acknowledge the support of the European Commission via the Marie Curie IAPP project MAGIC - Monitoring systems to Assess Geotechnical Infrastructure subjected to Climatic hazards (FP7-PEOPLE-2012-IAPP-324426). The authors also wish to acknowledge Dr Stephen Thomson from Transport Scotland for kindly giving access to the Road Infrastructure Project Tool v3.1.

\section{REFERENCES}

Ching, R.K.H., Sweeney, D.J. and Fredlund, D.G. (1984) Increase in factor of safety due to soil suction for two Hong Kong slopes, in Proceedings of the Fourth International Symposium on Landslides, 16th - 21st Sept 1984, Toronto, Canada, pp. 617-623

Construction Excellence (2008) Construction and Sustainable Development - Plain English, (as cited by UKGBC, 2013)

GeoSlope (2010) Seepage modelling with SEEP/W 2007 - An engineering methodology, 4th Ed., GeoSlope International, Alberta, Canada

Hughes, L., Phear, A., Nicholson, D., ET AL. (2011) Carbon dioxide from earthworks: a bottom-up approach, Proc. Instn. Civil. Engrs: Civil Engineering, vol. 164 (2) pp 66-72

Kerkes, D.J. and Fassett, J.B. (2006) Rapid drawdown in drainage channels with earthen side slopes, in Proceedings of the ASCE Texas Section Spring Meeting, 19th - 22nd April 2006, Beaumont, Texas

Tavakkoli, N. and Vanapalli, S. (2011) Rational approach for the design of retaining structures using the mechanics of unsaturated soils, in Proceedings of 2011 Pan-Am CGS Geotechnical Conference, 2nd - 6th Oct 2011, Toronto, Canada

USACE (2000) US Army Corps of Engineers - EM 1100-21913 Design and Construction of Levees - Engineer Manual, published by USACE

van Genuchten, M.T. (1980) A closed form equation for predicting the hydraulic conductivity of unsaturated soils, Soil Sci. Soc. Am. J., vol. 4, pp 892-898

Vanapalli, S.K., Fredlund, D.G., Pufahl, D.E. and Clifton, A.W. (1996) Model for prediction of shear strength with respect to suction, Can. Geotech. J., vol. 33, pp 379-392

Zielinski, M., Sanchez, M., Romero, E. and Sentenac, P. (2011) Assessment of water retention behaviour in compacted fills, Proc. Instn. Civ. Engrs. - Geotech. Engrg., vol. 164, pp 139-148 